January 2001

\title{
Mental Causation versus Physical Causation: No Contest
}

Crawford Elder

University of Connecticut Department of Philosophy, crawford.elder@uconn.edu

Follow this and additional works at: https://opencommons.uconn.edu/philo_articles

\section{Recommended Citation}

Elder, Crawford, "Mental Causation versus Physical Causation: No Contest" (2001). Philosophy Articles. 5.

https://opencommons.uconn.edu/philo_articles/5 
Crawford L. Elder

Department of Philosophy, U-54

University of Connecticut

Storrs, Connecticut 06269-2054

U.S.A.

\section{Mental Causation versus Physical Causation: No Contest}

James decides that the best price today on pork chops is at Supermarket S, then James makes driving motions for twenty minutes, then James' car enters the parking lot at Supermarket S. Common sense supposes that the stages in this sequence may be causally connected, and that the pattern is commonplace: James' belief (together with his desire for pork chops) causes bodily behavior, and the behavior causes a change in James' whereabouts. Anyone committed to the idea that beliefs and desires are states installed by evolution must, it seems, think something similar. For how can one see beliefs and desires as conferring selective advantage if not by supposing that, by causing bodily behavior in their subjects, they brought about changes in their subjects' surroundings? Yet many, many philosophers currently think or worry that mental causation is illusory (see, e.g., Heil and Mele 1993, or Macdonald and Macdonald 1995). Any physical changes which a mental state appears to cause can be viewed as a complex event involving microparticles, and for any such complex event, many philosophers suppose, there will have been previous microphysical occurrences sufficient to cause it. Barring routine overdetermination of such complex events, the apparent causation of mental events seems to be excluded. Nor does it help to say that some salient segment of the previous microphysical event just $i s$ the mental event, differently described (Davidson 1970). For describing the previous events as microphysical seems to spotlight the very features in virtue of which they did their causal work; the mental features seem epiphenomenal (Yablo 1992b: pp. 425-36; Yablo 1992a).

This paper argues that the complex physical events, which mental events seem excluded from causing, are not caused at all. For they are either accidents, in something like Aristotle's sense (Sorabji 1980: pp. 3-25), or coincidences, in a sense which David Owens has recently sharpened (Owens 1992). 
Each individual microphysical event comprised within such a complex does have a physical cause; but it does not follow, and is not true, that the complex, disjointed event as a whole does.

Mental causation, then, does not face competition "from below", from the microphysical level. Moreover it may on its own level be perfectly genuine. For the outcomes which mental events appear to bring about - the motions of limb and larynx, and the changes in the surroundings effected by these in turn—can be distinguished from the surgings and swarmings of microparticles which "realize" or "compose into" these outcomes. These macro-events may have a unified causal history which the swarmings do not, and the history may trace back to mental events.

\section{I}

If something causes the arrival of James' car at the supermarket, and if that arrival just amounts to such-and-such movements and state changes by such-and-such microparticles, then how can it fail to be true that something causes such-and-such movements and state changes by such-and-such microparticles? The answer, I argue, has to do with the relata of "__ is a cause of...".

Many philosophers would say that what causes, and what is caused, are events (Davidson 1967; Lewis 1986a: Part VI; Yablo 1992b). Yet there is considerable disagreement on how finely events are individuated. If a bolt in fact snaps suddenly, is the bolt's snapping the same event as the bolt's snapping suddenly? On the one hand, it seems easy to imagine a scenario on which it would be right to say: the bridge collapsed, not because of the bolt's snapping as such, but because of its snapping suddenly. Potentially distinct causal powers seem a reason to recognize actually distinct events. But on the other, both events are snappings, are of bolts, and both are sudden. The two events have all the same properties.

There are two ways to resolve the tension here. One is to retreat from the position that the relata of causation are events: a phrase such as "the bolt's snapping suddenly", one would argue, is just a nominalization of "that the bolt snapped suddenly", and the relata of causation are what "that..." claims report—states of affairs or facts (Bennett 1988: Chapters I and II). Since there is little temptation to say 
that the fact that the bolt snapped is the same fact as that it snapped suddenly-a point to which I will return-one thus accommodates the idea of a difference in causal powers. The other way is to argue that though the snapping and the snapping suddenly are events alike in all their properties, they differ in their constitutions, i.e. in which among the shared properties each has essentially and which merely accidentally (Yablo 1992a and 1992b). The bolt's snapping is only accidentally sudden—that very event could have occurred more slowly. But the bolt's snapping suddenly is sudden essentially. (Yet a third resolution is sometimes offered; but it is less promising than these, I think, for reasons presented later in this section.)

I maintain that viewing the relata of "__ is a cause of..." as events with both essential and accidental properties raises problems which can painlessly be avoided by viewing the relata as states of affairs. One problem is partly epistemological, partly a matter of how our alleged thought and talk about such events manages to refer to them. The other has to do with the mereology of such events.

To see the first problem, note to begin with that if events can be distinct from one another merely in virtue of their constitution-not because of differing at all in their properties - then routinely where one event is found there will be countless others superimposed. Suppose, for example, that the king falls from his horse in the afternoon (Owens 1992: p. 54). Then in one and the same spatio-temporal location there will be an event which essentially was a fall, but only accidentally was by a king; one which essentially was a fall by a king in the afternoon, and another which could equally have occurred in the morning; one which essentially was a fall from a horse, and another which involved a horse only accidentally. Then when someone says "that fall precipitated the bloody struggle for succession", how are we to judge whether she speaks truly—whether she was speaking of the right event? If the bolt's snapping as such cannot have been what caused the bridge to collapse, someone's falling in the afternoon, as such, cannot have been what caused a struggle for succession to the throne.

Defenders of the "events with essences" view typically recognize no problem here because they suppose that which event we are talking about can simply be read off from the phrasing we choose, at least when pressed for clarification. (Similarly, which event we are thinking about can be read off from 
how we think of it.) Thus if we elect to speak of "the king's falling violently from his horse", we are speaking of a fall which essentially was violent; if the phrase we elect is "the king's falling from his horse", we are speaking of a distinct event which only happened to be violent, and still could have occurred even if gentle (cf. Yablo 1992b: p. 412 and fn. 28). Reference is fixed, both for the phrases we use to designate events and for our thoughts about them, in just such a way that the modal beliefs which we express and entertain invariably come out true.

This is an extraordinarily optimistic view about reference. In other contexts-e.g. our talk and thought about physical stuffs and substances and phenomena-virtually no one has dared such optimism for roughly twenty-five years. On the contrary it is widely supposed that our thought and talk about physical stuffs and phenomena may misrepresent accidental properties as essential ones and vice versa, and may even attribute as essential a property which a given stuff or phenomenon has not at all. Kripke's story on which it turns out that gold has all along only appeared to be yellow, owing to atmospheric distortion, is admittedly fanciful (Kripke 1972: p. 118). But we did once really think of heat as by nature a kind of stuff, as caloric. We did for a long time think of common elements and chemical compounds as have essentially the surface-level features which they wear only in familiar terrestrial settings—e.g. "boils at $212^{\circ} \mathrm{F}$ ", "is malleable", "impedes the flow of electricity"- and failed to think of them as essentially characterized by their underlying microphysical structures. This failure lead us in turn to see facts as to how such compounds are created and destroyed as accidental rather than essential-e.g. that water is produced by oxidation of hydrogen.

But happily there is only one chemical compound water, only one element gold. We can tell which properties are non-accidentally projectible of it, and what its causal powers are, even if both inquiries will cost us empirical effort (Elder 1992). Yet at the place and time where the king fell, there are all manner of events, on the view under consideration. They are qualitatively indiscernible. But for all that they differ in what they can cause. Then how dare we hope to pick out the right event—in language or even the privacy of thought—when pronouncing on what caused the struggle for succession? Only by reassuring ourselves that if only we think hard enough and carefully enough, we will be bound to 
be thinking about the event with the right causal powers-and that if we choose carefully enough the phrasing that expresses our thought, we will be talking about the right event.

This stretches optimism too far, I suggest. The substance I think of as essentially malleable may be malleable only accidentally. The phenomenon I think of as a kind of fluid or stuff may be so not at all. But the event I think of as essentially king-involving and violent is bound to be both essentially, the view supposes, because it is the match with what I think that makes my thinking be about it. This makes aboutness be too marvelously cooperative a relation. Very few philosophers hold a parallel view for our talk and thought about physical stuffs and phenomena. The motivation for avoiding such a view comes from different sources, but mainly from a determination to bring reference, and aboutness generally, into the purview of natural science. It seems too much to believe that a relation which really figures in a scientific view of how our thought and talk interact with our environment could be rigged up so as to guarantee that certain of our beliefs (the modal ones) are true (Elder 1998). Just so, I suggest, with our thought and talk about events with essences.

The other main objection to the events with essences view of causal relata has to do with mereology. Events occupy spatio-temporal regions, and hence have parts. Moreover, it seems hard to deny that whatever causes a given event must cause all its parts. The objection then springs from the fact that some events comprise parts which seem, intuitively, only accidentally related to them: that very event could have occurred even if the part had not, and indeed the part could have occurred even if the larger whole in which it figured had not (cf. Owens 1992: pp. 57-60). Consider, for example, a particular crash of the stock market. Such an event comprises many panicky sell-offs by individual brokers. Suppose that this particular crash involved much panicky selling by Bullish Joe, but that Joe, being bullish, would not ordinarily have joined the stampede. He did so only because he had just received word that his wife had a serious illness, and this had put him in an uncharacteristically vulnerable frame of mind.

The precise form the objection now takes depends on the analysis one gives of "__ is a cause of...”. In the next section I shall offer mine. But the general shape of the objection can be discerned 
given merely the point that, on almost everyone's analysis, causation involves an element of sufficiency and an element of necessity. The cause of outcome $e$ must, first, be something that was sufficient, at least in the circumstances, to ensure $e$ 's occurrence; second, something without which e would not, in the circumstances, have occurred at all.

On what did this crash of the stock market crucially depend - to what previous development can we point and say, "if only this had not occurred, the market crash would not have ensued"? Perhaps bank failures in Asia were crucial, or some pronouncement by the Chairman of the Federal Reserve Board. But certainly not Joe's receiving the bad news about his wife. Even if Joe had received no such news, and had himself resisted the stampede, the market would have crashed anyway. So viewed under its aspect as a necessary condition, the cause of the collapse was not the cause of Joe's panicky selling. Yet the crash in part consisted in Joe's panicky selling.

And what sufficed to make the market crash? Perhaps again the Asian bank failure, or Alan Greenspan's remarks, or perhaps the two in combination. But these two circumstances, bad as they were, were not what got Joe to sell. For had it not been for the bad news about his wife, Joe would not have sold at all. Viewed under its aspect of sufficient condition, the cause of the crash was not the cause of Joe's panicky selling. Yet the crash in part was Joe's selling.

Both objections canvassed here against events as causal relata stem from distinguishing essential from accidental properties of events. Yet that distinction seems required to individuate events finely enough to suit them for causal roles. Some defenders of events as relata do indeed contend that what needs to be fine-grained is not the events that fill causal roles but the generalizations in virtue of which they do so (Davidson 1967, §III). Thus it is said that the bolt's snapping must be able to cause anything that the bolt's snapping suddenly does, since the snapping after all was sudden. But this view makes it hard to assess whether the snapping can qualify as cause, under the cause's aspect of necessary condition. The nearest possible world in which the snapping does not occur is one in which an event like it does occur, but the snapping itself does not—the look-alike event lacks one of the snapping's essential 
properties. What then are the snapping's essential properties? It occupancy of a causal role requires after all the distinction between accidental and essential properties.

Can events be preserved as relata by fine-tuning the account of what is and is not essential to them? There is, I think, an aspect of artificiality to the entire question of how finely events are individuated. Perhaps Bennett (1988: pp. 135-42 and 18-19) is right that our concept of an event is too "lumpish" and "inexact" to sustain informative answers to such a question. In any case the individuation of facts is a far more clear-cut matter: two "that..." claims report the same fact iff they attribute, to the same property-bearers, the same properties (Elder 1996a). Thus "that the bolt snapped suddenly" reports a different fact from "that the bolt snapped"- - the former attributes a property which the latter does notand recognizing the difference does not require us to posit two qualitatively indiscernible things which differ only in their constitutions. Moreover, since facts do not occupy spatio-temporal regions, they do not in any straightforward sense have parts, and no question arises whether what causes them causes their parts. Facts provide, painlessly, the fine-grained relata we want for "__ is a cause of..."?

\section{II}

The relata of causation are fine-grained: what brings it about that James' car arrives at Supermarket S may not thereby bring it about that such-and-such microparticles undergo such-and-such motions and state changes at just that time and place, and vice versa. But what positive reason might there be for supposing that while something brings about the former state of affairs, the latter state of affairs has no cause at all? In the present section I begin on an answer by offering an analysis of “__ is a cause of...". In subsequent sections I argue that the latter state of affairs is either an accident or a coincidence, and that in either case it can have no cause.

But while the consequences I draw from my analysis of “__ is a cause of...” are controversial, I think the analysis itself is not, at least not particularly so. It is merely a modified version of Bennett's analysis in terms of NS conditions (Bennett 1988: Ch. III), and has elements in common with every main 
analysis currently on offer. Perhaps the conclusions are surprising because of ancillary ontological claims on which they partly depend, e.g. that fusions of objects are not objects in their own right-more on this in the final section. Or perhaps the surprise is due merely to the fact that the bearing of causation on accidents and coincidences is not a commonly explored topic. In any case I have not space to offer a concerted defense of my analysis. If it seems to need one, please read this paper as advancing a provisional claim: if a cause is one species of NS condition, then mental causation faces no competition from below.

The basic idea then is that a cause of outcome $e$ is a state of affairs $c$ which figures indispensably in a set of circumstances jointly sufficient to ensure that $e$ obtains. Typically a cause will not by itself compose all of such a set-i.e., typically what qualifies as "a cause of $e$ " will not strictly qualify as "the cause of $e "$-but will call upon distinct circumstances, e.g. background conditions, for sufficiency to produce $e$. Also typically, the set in which $c$ indispensably figures will be just one among several by which $e$ could have been produced. So Mackie (1965) had good reason to describe the typical cause as an INUS condition of its effect, as an Insufficient but Necessary part of a set of circumstances Unnecessary but Sufficient to produce the effect. At the same time it is unduly restrictive to define a cause as an INUS condition. A state of affairs which by itself ensures the occurrence of $e$, and is all that could ensure the occurrence of $e$, should qualify as a cause of $e$. A cause is fundamentally an NS condition (a Necessary part of a Sufficient condition) of its effect.

Now for details. First, it is crucial that the set of circumstances in which $c$ is a key ingredient has the right sort of sufficiency for $e$. If $c$ figures crucially in a set of circumstances logically sufficient for $e$ 's obtaining — or in a set which is, so to speak, constitutively sufficient for $e$ 's obtaining—it will be counterintuitive to bill $c$ as a cause of $e$.

Here is an illustration of the first sort of counterintuitive result. I go to the agora with the intention of seeing a play, and my debtor goes to the agora for an unrelated reason, and by accident we arrive at the agora at the same time-a lucky accident, since it results in my recovering my debt. Aristotle, from who the example is taken, holds that the accident of our arriving at the agora 
simultaneously has no cause, and soon I will argue that he is right. But for now my point is that it would be counterintuitive to hold that our arriving simultaneously does indeed have a cause, and that it is caused by my arriving at the agora (as in fact I did) at precisely 4:03. For causes must be distinct from their effects. Yet my arriving at 4:03 is our arriving simultaneously—or rather is, together with my debtor's arriving (as in fact he did) at 4:03, part of a set of circumstances which logically amounts to our arriving simultaneously.

For the other sort of counterintuitive result, consider the complex surging and swarming of microparticles which "realizes" or "composes into" James' arrival by car at Supermarket S. Suppose that a crucial element in this sprawling microphysical event is the surging in a certain direction of so-and-so many carbon atoms configured in biochemical compounds, surrounded by so-and-so many iron atoms arranged in lattices that "realize" steel, all occurring at a certain distance above so-and-so many atoms of silicon bonded with other atoms in molecules that add up to pavement. The arrival of James' component carbon atoms in just that region should not count as a cause of James' arriving at the parking lot, again for the reason that causes must be distinct from their effects. That those atoms arrive in that region is, to be sure, a different fact (a different state of affairs) from that James arrives in the parking lot. But their connection is still too close for the former to qualify as cause of the latter. The reasons for denying a causal connection here indeed go fairly deep. The whole worry about mental causation stems from the thought that the neural—ultimately, microphysical—states of affairs which "compose into" or "subvene" James' decision to go to S may really do all the causal work which James' decision appears to. But the causal work which the microphysical goings-on are thought to do does not include "composing into" or “subvening" James' decision itself. For their causal work is thought to be underwritten by the laws of physics, and the laws of physics do not quantify over decisions (Witmer 1998). "Subvening", "composing into", is thought of as a non-causal relation between micro-events and macro-events. Similarly non-causal then is the relation between the surging of James' carbon atoms and James' arriving in the parking lot. 
A cause of $e$, then, is an indispensable component in a set of circumstances which jointly are causally sufficient—at any rate, not logically or constitutively sufficient—for the occurrence of $e$.

Two other details must now be considered: first, that something Bennett calls "the continuity condition" must be added to the basic account of a cause as an NS condition; second, that "the continuity condition" cannot, despite what Bennett says, supplant that basic account.

I toss a lighted match towards the top of an open gasoline drum, Bennett's example runs, and thereby top off a set of conditions jointly sufficient for the house's being in ruins an hour later. But my toss does not cause the house to be in ruins. For a bomb lands on the house at the instant I launch the toss. Its causation preempts that of the match (Bennett 1988: pp. 45-46). What the possibility of such preemption shows, as Bennett rightly notes, is that a t every moment between a putative cause and its would-be effect, a circumstance must obtain for which the immediately preceding circumstance was an NS condition, and which in turn was itself an NS condition of the immediately following circumstance. When the bomb intervenes, it assumes the role of NS condition for the next momentary circumstance in the series leading up to the house's being in ruins, but the bomb's presence is not itself anything for which any stage of my match-toss was an NS condition.

But Bennett also thinks that we can now drop the requirement that $c$ be itself an NS condition of $e$, and let the continuity condition do all the work of analyzing $c$ 's causing $e$ : it will be enough, Bennett says, that each intervening stage between $c$ and $e$ be linked NS-wise to its immediate predecessor and successor (Bennett 1988: pp. 46-49). This relaxation of the analysis, I maintain, yields counterintuitive results. For the continuity condition alone can be satisfied by the following sort of chain. P is an NS condition for $\mathrm{Q}$ and $\mathrm{Q}$ is an NS condition for R. But $\mathrm{P}$ calls on certain background conditions for causal sufficiency to produce Q, and Q in turn calls on different background conditions for causal sufficiency to produce R; moreover, the conditions Q calls upon get assembled later than the first set, and neither P itself nor the first set plays any role in bringing about the later set. Then so far as P's occurrence goes, it is a pure coincidence that somewhat later, $\mathrm{R}$ comes along. P cannot plausibly be said to cause $\mathrm{R}$. 
Consider, as illustration, this lovely example from David Owens (Owens 1992: pp. 18-19). I contract a disease which will kill me in six months unless treated with drug A. But so noxious are A's side-effects that A itself will, unless counteracted, kill me within a year. I take A. After nine months someone discovers drug B, which suppresses A's side-effects—but only for two years, at which point the patient at length succumbs. I then take drug B, and two years after the original diagnosis, I am still alive. Question: what causes me, two years after the original diagnosis, to be free from the clutches of death? Not that I took drug A, Owens maintains. On the contrary: it is mere coincidence that two years after taking A, I am still alive. I think this verdict is correct, though for slightly different reasons from those Owens gives. $^{3}$

The central question is whether my taking drug A played a Necessary part in a set of events Sufficient, given the circumstances, for my being alive today. The answer is No. The set of circumstances in which my taking drug A played a part— the set which my ingestion of A then engaged for its sufficiency to keep me alive nine months longer-included no circumstances at all connected with the development of drug B. Circumstances which would ensure development of B may then have obtained. But they were not causally involved in my living on for nine months more. Thus my taking A was not an NS condition of my being alive today-even though it was an NS condition of my being alive nine months later, and my being alive nine months later was an NS condition of my being alive today. So “__ is an NS condition for..." is not transitive. Consequently, neither is "__ is a cause of..." —_a point of importance in section IV.

III

I have claimed that the complex microphysical mêlée which realizes James' arrival at Supermarket S must be viewed as either an "accident" in Aristotle's sense or as a "coincidence" in David Owens' sense, and that in either case it has no cause. Let me warm up for the needed argument by 
discussing simpler cases of what I mean by an "accident" and a "coincidence", together with the reasons for thinking that these simpler cases lack causes.

The joint arrival at the agora of my debtor and me can be viewed as an amalgam of two specific states of affairs: my arriving at the agora at exactly 4:03, and my debtor's arriving there at exactly 4:03. Alternatively, it can be viewed as a unitary relationally-defined state of affairs: my debtor and I arrive at the same time as one another. The amalgam of two states of affairs is an example of what I call a "coincidence". The unitary relational state of affairs is an example of an "accident".

My focus in this section will be on accidents. So let us ask what, if anything, brings it about that my debtor and I arrive at the same time as one another. Was some circumstance distinct from our simultaneous arrival causally sufficient to produce it? If so, how could one spot such a circumstance? In actual empirical inquiry, the main evidence for causal sufficiency is something which experimentalists call "invariance" (Woodward 1992: pp. 201-210; cf. Elder 1992). This is a finding that different values of a determinable which subsumes a putative cause are reliably tied to commensurately differing values of a determinable which subsumes the putative effect. Thus a low level of calcium in the diet is implicated as a cause of osteoporosis by the finding that, ceteris paribus, the lower the intake of calcium, the more severe the porosity of the bones.

To identify a previous circumstance causally sufficient for the simultaneity of my arrival and my debtor's, then, we need to ask what sorts of previous circumstances would have been tied to arrivalrelations more and more different from simultaneity. So we need first to imagine my arrival's having been just a bit earlier than my debtor's, or vice versa; and then that one of us arrived earlier by an even greater margin, so that one of us nearly missed the other in the agora; etc. If something actually sufficed causally for simultaneity in our arrivals, variations on that something, first mild and then sharp, must seem likely to have gone together with arrival-relations more and more different from simultaneity.

It now seems obvious what sort of previous circumstance we must look for. We must find, among all those factors causally responsible for my arrival at the agora, and all those causally responsible for my debtor's, some relational circumstance that ties a factor contributing to my arrival to a factor 
contributing to my debtor's. For it is variations on that sort of circumstance, first mild and then sharp, that would be tied to arrival-relations more and more different from simultaneity.

But there is no such circumstance. For ex hypothesi the factors that got me to go to the agora were unconnected with those that got my debtor to go. No one event triggered both the causal chain which led to my arriving at the agora and the chain which led to my debtor's arriving there. So nothing brought relations between my debtor and me into play, causally. Relations between us remained causally inert: they never made for matching rates at which the causal impact of a common cause got propagated along the two causal chains. (For contrast, suppose my debtor and I had simultaneously heard the town crier announce that nuggets of gold free for the taking had been dumped in the agora; then that we live at places equidistant from the agora, and are equally fleet afoot, are NS conditions for our arriving there simultaneously.) This is indeed definitional of what I am calling an "accident": the outcome is relational, but the states of affairs thus related have unconnected causal backgrounds.

So the accident of our arriving simultaneously, like all accidents, has no cause. No previous circumstance causally sufficed for its occurrence. The causal processes of the world, to speak metaphorically, did not grab our joint arrival by its simultaneity when they pulled it into existence. Rather they grabbed our joint arrival at two different points, independently, and pulled: the simultaneity just came along for the ride.

The microphysical mêlée which realizes James' arrival at Supermarket S can itself be viewed as a unitary relationally-defined state of affairs, on a par with my debtor's arriving at the agora at the same time as I do. At first blush, I admit, it seems more natural to view it as an amalgam of innumerable states of affairs-that such-and-such a microparticle is undergoing such-and-such a motion at that precise location, while such-and-such others are undergoing precisely that sort of motion in precisely that other location, while yet another microparticle is doing such-and-such there, etc. But just as there are contexts in which the relevant question is what caused my debtor and me to arrive at the same time as one another, regardless of whether I arrived at exactly 4:03 and whether he did, so there may be a parallel question concerning the microphysics of James' arrival at S. Perhaps it is of interest to know, not what caused 
exactly such microparticles as were present in that parking lot to make exactly such motions and undergo exactly such state changes as in fact occurred, but rather why some microparticles or other, clustered together in some one of the ways that would compose into a car, were collectively moving above some other cluster of microparticles (or other), configured in one of the ways that would compose into pavement, while collectively encompassing some one or other of the clusters of microparticles that would have composed into James.

But would this relationally-defined microphysical development be just another accident—could it be said to have a cause? To find a cause for the simultaneity of my arrival and my debtor's, we looked for a previous circumstance, variations in which would have gone together with variations in arrivalrelations-hence a relational circumstance that figured as an NS condition for my debtor's arrival or for mine. To find a cause for one cloud of microparticles' moving in a certain way relative to another, while yet surrounding a third cloud, we would have to identify relational circumstances whose relata were whole clouds, relational circumstances which causally influenced—were NS conditions for-motions and state changes done by individual microparticles within each cloud. Pretty clearly, it would be easier to find the Holy Grail. Behaviorally, microparticles pay heed to their immediate neighbors in atoms, and atoms to their immediate neighbors in molecules and lattices and swarms. But microparticles are physically indifferent to the macro-groupings into medium-sized objects which common sense (and folk physics) imposes upon them (Elder 2000 and Elder forthcoming). A fortiori, they are physically uninfluenced by relations between the macro-group to which they belong and other macro-groups.

The microphysical mêlée which realizes James' arrival, if viewed as a relationally-defined development, has no cause.

IV

Then are the prospects for finding a cause improved if we view that mêlée as a coincidence? A coincidence, in the sense I take from David Owens, is a compound outcome which divides into states of 
affairs caused independently of one another (Owens 1992: Ch. 1). That is, for at least one of the component states of affairs, no previous development which rounds out a set of circumstances causally sufficient for it also rounds out a set causally sufficient for any other component state of affairs. The example given earlier is the case in which my debtor and I both arrive at the agora at exactly 4:03. For the developments that got me to go to the agora are ex hypothesi distinct from those that got my debtor to go.

Following Owens I hold that a coincidence has no cause, but the position could be disputed. One might reason as follows. Something brought it about that I went to the agora at exactly 4:03, and something brought it about that my debtor went there exactly then. But then there is a compound state of affairs composed of these two NS conditions taken together, and it is itself an NS condition for both components of the coincidence. That it was the case both that I at 4:00 conceived a burning desire to see a play, and that at 3:45 my debtor conceived a languid desire to buy a bracelet, caused it to be the case that both of us arrived at the agora at 4:03.

I suggest that this reasoning assumes too casually that "___caused it to be the case that..." (or “__ is an NS condition for...”) is agglomerative_-that if P causes Q, and R causes S, (P \& R) causes (Q $\&$ S). The question "what caused the left front tire on my car to go flat?" undoubtedly has an answer. The question "what caused the Indonesian economy to collapse?" likewise has, let us allow, an answer. But consider: "what caused my left front tire to go flat and the Indonesian economy to collapse?". The answer, intuitively, is that nothing did; the two outcomes have different causes. But then "__ is an NS condition for..." is not agglomerative (cf. Owens 1992, pp. 11-15).

If the intuition here seems suspect, consider more closely the compound state of affairs composed of whatever did cause the Indonesian collapse and whatever caused my flat tire. That compound circumstance is not an NS condition for my tire's going flat, since its economic component is dispensable. Nor is it an NS condition for the Indonesian collapse, since its road-surface component is dispensable. How then could that compound circumstance be an NS condition for both that my tire went flat and that the Indonesian economy collapsed? ${ }^{4}$ 
Suppose then we do view the complex microphysical development which realizes James' arrival at the supermarket as a coincidence — as an amalgam of innumerable microphysical states of affairs, each of which is caused independently of almost all the others. In that case we will have to admit that the complex microphysical development does not have a cause.

But is it really true that each individual microphysical state of affairs in this disorderly complex is caused independently of almost all the others? Many of these individual states of affairs do descend from causal chains which overlap at one point. Some event within James' brain, which realized James' decision about today's best price on pork chops, triggered firings which triggered firings... which sent signals down James' motor nerves, which in turn triggered outcomes which triggered outcomes...which led to James' being present in the parking lot. At the level of microparticles, one movement or state change of a particular microparticle led to a movement or state change by a different microparticle, and so on. But each successive motion or state change of a microparticle called on new surroundings and background conditions, caused independently from the previous surroundings and conditions, for its causal sufficiency to produce the next.

So the situation is actually parallel to the one in which my taking drug A figured in a causal chain which led to my being alive two years later, in another causal chain which led to a debt to the manufacturer of A being entered as a lien upon my estate, in another which led to my winning a contest open only to people who survived for six months after contracting my disease, in another which led to an article about me in last week's newspaper commissioned by a hard-pressed Features editor. That all four of these outcomes befall me is a coincidence, even though the causal chain leading to each overlaps at some point which the causal chain leading to every other. For no one previous development topped off sets of circumstances causally sufficient to produce each of the four outcomes. The only previous development that is even a candidate is my originally taking drug A. But at the time I took drug A there were no sets of circumstances causally sufficient to produce my survival to this day, or my victory in the contest, or the appearance of the newspaper article. These depended on background conditions assembled 
later, by causally independent processes. And that is enough to entail that the four outcomes are caused independently of one another. After all, “__ is an NS condition for..." is not transitive.

Just so then for the innumerable microphysical states of affairs within James' body, and surrounding it, which realize his arrival at the parking lot. Many descend from causal chains that overlap at some point. But even these many do not have an NS condition in common. They are caused independently of one another. They do compose a coincidence. The compound outcome which they compose has no cause.

\section{$\mathrm{V}$}

Only a desperate maneuver remains, I think, by which to rescue the idea that the microphysical mêlée which realizes James' arrival has a cause. It involves gathering the individual microphysical causes of each individual microphysical state of affairs comprised in that mêlée, packing them all together as a single event, and pronouncing it the cause of the mêlée itself. But it differs from the maneuver of agglomerating the causes into a single compound event. For it treats the event produced by the packing as single and non-compound, as a matter of one property-bearer's possessing one property.

This may sound like an amazing claim! But the idea would be that there is such an object as the fusion of all the microparticles that figure in the individual causes of individual components of the mêlée. The single property which this fusion has, its having of which causes the mêlée to occur, would in turn be a structural property or structural universal. A structural property is a property which only wholes composed of parts can have, and consists in the parts' being, respectively, thus-and-and-such, such-andsuch, and so (Armstrong 1997: pp. 32-38). The property of being a methane molecule is the standard example. For something to be a methane molecule is for it to contain one part which is a carbon atom, this part being bonded in such-and-such a way to another part which is a hydrogen atom, bonded similarly to yet another hydrogen atom, and bonded similarly to yet two more. 
It seems hard to deny that there really are structural properties, if there really exist any properties at all. But it is not nearly so clear that there really exist fusions. One standard argument for fusions involves a classic shift in the burden of proof: if objects $a$ and $b$ both exist, the argument runs, it would be arbitrary to deny that the fusion of $a$ and $b$ also exists, since saying that it exists really adds nothing to the claims that $a$ exists and that $b$ does-it is, in Armstrong's phrase, an "ontological free lunch" (Armstrong 1997: pp. 12-13 and 185). ${ }^{5}$

In the present context, however, the affirmation of fusions would add a great deal. For it would bear not only on what, if anything, causes the microphysical mêlée subvening James' arrival; it would bear also on the nature of the microphysical mêlée itself. That swarming and surging of microparticles would no longer be a compound state of affairs, but a single one. It would no longer divide into parts caused independently of one another, because it would no longer divide into parts at all. It would no longer be a coincidence. It would be something that is caused.

Precisely for that reason, the employment of fusions envisioned here would be indefensible, at least in the absence of (much!) further argument. Recognizing fusions was supposed to do what Wittgenstein said philosophy always does-it was to leave everything unchanged. But recognizing fusions in this context would cause massive change. So an entirely new rationale would have to be devised. ${ }^{6}$ 


\section{Footnotes}

${ }^{1}$ The phrase "compose into" is from Sturgeon 1998. Sturgeon argues well that no one now can "see how quantum events build into the splendour of macro reality" (p. 424). But if no one can see how micro events compose into macro events, the very concept of "composes into" may harbor confusionshence my (temporary) use of scare quotes. Melnyk (1997) makes similar claims about the supervenience of macro events on micro events-in other words, about how the latter subvene the former-and hence my scare quotes around the first few tokens here of "subvenes".

${ }^{2}$ Yablo finds fact causation painful: "Facts have their reality by timelessly and placelessly obtaining" (1992b, fn. 29, p. 440), but causes and effects are at times and in places. No one who holds a tensed view of time, as I do, will agree without hearing considerable argument that facts obtain timelessly. What then about placelessly? If some state of affairs involving the bolt causes the bridge to collapse, then true enough, the bolt and the bridge must both have locations; but why need the fact that the bolt snapped-i.e., the bolt's snapping — have a location to bring it about that the bridge collapsed? Cf. Bennett 1988: pp. 22-23.

${ }^{3}$ Owens takes coincidence to be conceptually prior to cause: on his analysis, a cause is that which "ensures that its effects are no coincidence" (1992: p. 2). There is one merely apparent problem with this analysis, and one real one. The merely apparent problem is that such-and-such outcomes qualify as c's effects only if c qualifies as their cause, and the analysis therefore smuggles the analysandum into the analysans. This problem is merely apparent since "its effects" can be read just referentially, not attributively: it serves to point out those outcomes, outcomes which in fact will turn out to be $c$ 's effects. The real problem is that "ensures" means "brings it about that", on all plausible readings, and so $c$ 's being a cause is being analyzed by c's causing something. Probably the charitable reading is that by "ensures" Owens means something closer to "is". That is, a cause is that in virtue of which its effects are no coincidence. That the effects all occur would be a coincidence, the thinking would run, if there were not some common circumstance necessary and sufficient for all of them-or, more liberally, some common 
necessary condition for them or some common sufficient condition (p. 24) - and so $c$ is what keeps by effects from being coincidental by being that common necessary and sufficient (or necessary, or sufficient) condition. This reading takes Owens' analysis to be close to the analysis I endorse. (But not close enough: Owens still would not be in a position to offer the argument against transitivity which I give at the very end of this section, or the argument against agglomerativity which I offer in §IV.) But it would be strikingly inconsistent with Owens' tolerance of agglomerated necessary and sufficient conditions, and his consequent concession (p. 22) that there are necessary and sufficient conditions for coincidences.

${ }^{4}$ Here is a different way of putting the point. Suppose we wrote down all the laws of nature; all the background circumstances called upon, by whatever did cause the Indonesian economic collapse, for its causal sufficiency; and all the circumstances called upon, for causal sufficiency, by the piece of glass that caused my tire to go flat. Suppose we then asked: what extra premises need to be added, to render logically valid the inference to "the Indonesian economy collapsed and my tire went flat"? Then the point would be that there is no prospect of inferring that conjunction directly. For there are no laws of nature governing the co-occurrence of economic upheavals and tire deflations—or so I have argued (Elder 1996b and 1992). Rather the argument would have to infer one conjunct and then the other. And on the way to inferring the conjunct about the economic collapse, there would be no need for premises (or conjuncts of premises) dealing with road surfaces; on the way to inferring that the tire went flat, no need for premises (or conjuncts) about overextended credit and other financial details. So at no point in the argument would there be any need for a conjunctive premise about economic dangers in Indonesia and messy road surfaces here. The agglomerated state of affairs reported by such a sentence is not an NS condition of anything.

${ }^{5}$ Lewis' argument for fusions is more complex: no principled reason can be given why the sum of the microparticles in the parking lot does not compose an object, while the microparticles in James' car do compose an object (viz. the car), since only a vague boundary can be drawn between the 
microparticles within James' car and those without it, and real objects cannot be vaguely delimited (Lewis 1986b: pp. 212-13). But even this argument starts with a shift in the burden of proof. The question Lewis addresses is how composition (into objects) can be "restricted" to just such objects as cars.

${ }^{6}$ For comments on previous drafts, I am grateful to Austen Clark, Joel Kupperman, Tom Bontly, and most especially John Troyer. 


\section{References}

Armstrong, D. M. 1997: A World of States of Affairs. Cambridge: Cambridge Univ. Press.

Bennett, Jonathan 1988: Events and Their Names. Indianapolis: Hackett.

Davidson, Donald 1967: “Causal Relations”. Journal of Philosophy, 64, pp. 691-703. 1970: "Mental Events". In Foster and Swanson 1970.

Elder, Crawford forthcoming: "Physicalism and the Fallacy of Composition." Philosophical Quarterly. 2000: "Familiar Objects and the Sorites of Decomposition." American Philosophical Quarterly, 37, pp. 79-89.

1998: “What versus How in Naturally Selected Representations”. Mind, 107, pp. 349-63. 1996a: "Content and the Subtle Extensionality of “__Explains...". Philosophical Quarterly, 46, pp. 320-32.

1996b: “Contrariety and 'Carving Up Reality””. American Philosophical Quarterly, 33, pp. 277-

89.

1992: “An Epistemological Defense of Realism about Necessity”. Philosophical Quarterly, 42, pp. 317-36.

Foster, Lawrence and Swanson, J. W. 1970: Experience and Theory. Amherst: Univ. of Massachusetts Press.

Heil, John, and Mele, Alfred 1993: Mental Causation. Oxford: Oxford Univ. Press.

Kripke, Saul 1972: Naming and Necessity. Cambridge, Mass.: Harvard Univ. Press.

Lewis, David 1986a: Philosophical Papers. Oxford: Oxford Univ. Press. 1986b: On the Plurality of Worlds. Oxford: Blackwell.

Macdonald, Cynthia, and Macdonald, Graham 1995: Philosophy of Psychology. Oxford: Blackwell. Mackie, J. L. 1965: “Causes and Conditions”. American Philosophical Quarterly, 2.4, pp. 245-64. 
Melnyk, Andrew 1997: "On the Metaphysical Utility of Claims of Global Supervenience”. Philosophical Studies, 87, pp. 277-308.

Owens, David 1992: Causes and Coincidences. Cambridge: Cambridge Univ. Press.

Sorabji, Richard 1980: Necessity, Cause and Blame. Ithaca: Cornell Univ. Press.

Sturgeon, Scott 1998: "Physicalism and Overdetermination". Mind, 107, pp. 411-32.

Wittmer, D. Gene 1998: "What Is Wrong with the Manifestability Argument from Supervenience". Australasian Journal of Philosophy, 76, pp. 84-89.

Woodward, James 1992: "Realism about Laws". Erkenntnis, 36, pp. 181-218.

Yablo, Stephen 1992a: "Mental Causation”. Philosophical Review, 101, pp. 245-80. 1992b: "Cause and Essence". Synthese, 93, pp. 403-49. 